\title{
The Pathogenesis of Prostate Cancer
}

\author{
Toby B. J. Murray \\ Urology Department, Frimley Park Hospital, Portsmouth Rd, Frimley, Camberley \\ GU16 7UJ, UK
}

Author for correspondence: Toby Murray, Urology Department, Frimley Park Hospital, Portsmouth Rd, Frimley, Camberley GU16 7UJ, UK. Email: toby.murray@nhs.net

Doi: https://doi.org/10.36255/exonpublications.prostatecancer.pathogenesis.2021

\begin{abstract}
Prostate cancer is a major cause of pathology in men world-wide and is age-related. Rare in the under 40s, a third of all those over 80 have been shown to have prostate lesions at autopsy. Both hereditary and molecular influences appear to be involved in the pathogenesis of the condition. Androgenic receptors play a major role in most, but not all, prostate cancers. The cell type involved is related to the aggressiveness of the malignancy. Of those that develop the disease, some die with prostate cancer, others because of it. Over 90\% of the cancers are adenocarcinomas. The likelihood of progression of the disease can, but only to a degree, be predicted on histological examination, according to the Gleason Scale and its modifications. These assess degrees of tissue differentiation. Use of blood levels of prostate specific antigen levels as an indication of the activity of tumors is also not straightforward. Our understanding of the disease mechanisms needs further expansion if we are to advance diagnosis of aggressive tumors and develop more effective therapies.
\end{abstract}

Keywords: androgenic regulation; neuroendocrine cells; prostate cancer; prostatic intraepithelial neoplasia; transrectal ultrasound

In: Prostate Cancer. Bott SRJ, Ng KL (Editors). Exon Publications, Brisbane, Australia. ISBN: 978-0-6450017-5-4; Doi: https://doi.org/10.36255/exonpublications.prostatecancer.2021

Copyright: The Authors.

License: This open access article is licenced under Creative Commons Attribution-NonCommercial 4.0 International (CC BY-NC 4.0) https://creativecommons.org/licenses/by-nc/4.0/ 


\section{INTRODUCTION}

In the United Kingdom (UK), prostate cancer is the most prevalent neoplasm in males, accounting for $13 \%$ of total cancer cases (1). Prostate cancer contributes to $7 \%$ of all cancer-related deaths, making it the second most common cause of cancer death in males. Age-standardized incidence rates for prostate cancer have increased by $41 \%$ since 1993 although mortality rates have dropped 10\% in the last decade (1). It is a heterogenous disease, with a wide scope of disease pathogenesis from asymptomatic and prolonged, where men die with the disease, to severe malignancy where men die from it or have significant morbidity. At the turn of the century, a Spanish study evaluating prostate histology at autopsy identified that men from the third decade onwards have neoplastic lesions of the prostate and 33\% of the male population in their eighth decade have prostate cancer (2). In addition, prostate cancer is the most commonly diagnosed malignancy in older men (over the age of 65) worldwide, especially in highly developed countries (Australia, New Zealand, Northern and Western Europe, and North America) (3-5). The high prevalence of the disease can be attributed to the volume of cases identified through prostate specific antigen (PSA) testing, especially in the United States (6). However, prostate cancer screening has been surrounded by controversy and can be seen as an ethical dilemma. Studies have shown that distinguishing between indolent pathology and aggressive tumors using PSA levels alone is insufficient as it is not cancer-specific (7). It is also a challenge as high PSA levels do not directly correlate with pathogenicity and requires further investigations through multiparametric magnetic resonance imaging (MRI) and histology. Therefore, early diagnosis often leads to harm to patients via overdiagnosis and unnecessary treatment (radical surgery, radiotherapy and chemical castration) leading to reduced quality of life $(\mathrm{QoL})$ and psychological trauma knowing they have a cancer diagnosis (7). This chapter aims to address the developmental processes involved in prostate cancer including hereditary and molecular components.

\section{PROSTATE CARCINOGENESIS}

The prostate is a male sex glandular structure, derived embryologically from the urogenital sinus. The glandular tissue consists of multiple secretory units (acini), consisting of ducts lined with epithelial cells, that converge and open either side of the verumontanum. Its main functions are to provide force to ejaculate semen and to add nutrient-rich alkaline fluid to the semen to maintain spermatic health post-ejaculation and enhance fertility (8). The gland is highly susceptible to malignant transformation and as a consequence has a higher rate of malignancy than other structures in the urogenital tract. Studies have shown that the characterization of prostatic carcinogenesis is closely linked to organogenesis embryologically, including a heavy reliance on androgenic hormone signaling, such as testosterone, as well as debated potential links to other embryological signaling pathways such as Sonic Hedgehog expression (Shh) and inappropriate expression of the Gli-1 oncogene leading to stromal tumor growth and proliferation (9-11). 


\section{HISTOPATHOLOGY OF PROSTATE CANCER}

Prostate cancer involves malignancy primarily of the epithelium and is thus classed as a carcinoma. There are rarer subtypes of prostate cancer such as sarcomas (derived from mesenchyme) and lymphomas (12). Neoplastic changes normally arise in the peripheral glandular tissue of the prostate. The prostatic epithelium comprises of luminal, basal and rare neuroendocrine (NE) cell types (13). The epithelial luminal cells, expressing androgen receptors (ARs), cover the internal surface of the prostatic ducts and secrete prostatic fluid and the glycoprotein PSA. They are surrounded by basal cells, that produce proteins used for fluid production and the formation of the acinar basement membrane that separates the epithelial acini from the prostatic stroma. These cells have interspersed NE cells. Both basal and NE cell types are deficient in ARs and thus are not testosterone or androstenedione dependent (14). Fibroblasts, smooth muscle and infiltrating immunological cells combine together to form the stroma of the prostate. There is currently a large interest in identifying the cell type that is responsible for oncogenic transformation (cell of origin) in prostate cancer due to the variability of disease progression and the unpredictability of treatment response $(13,15)$. Prostate cancer biopsies show tissue deficient in basal cells, leading to questions as to whether there is a form of basal cell differentiation into luminal cells or that luminal cells are the primary cell of origin (13). Using these cell types, it has been hypothesized that tumors arising from luminal cells will be more aggressive than those arising from basal cells (16). About 90-95\% of prostate cancers are acinar adenocarcinomas that arise from the peripheral prostatic gland (17). Histological diagnosis is made by assessing the loss of surrounding basal cells, loss of normal glandular architecture, including the disruption to the epithelial-stromal basement membrane, and nuclear atypia of luminal cells (Figure 1) (18). Aggressiveness of the adenocarcinoma is reflected in the degree of differentiation on histology. This is graded using a Gleason Score grading system, last modified in 2014 by the International Society of Urologic Pathology (ISUP) (19). This stratifies histological findings of prostate cancer with prognostic behavior, that is, the 5-year biochemical recurrence (BCR) risk following radical prostatectomy (Table 1) (20). Prostate cancer is staged using the 2018 classification for adenocarcinoma of the prostate based on primary tumor (T), lymph node involvement (N) and metastases (M). Prostate cancer typically involves regional lymph nodes in the pelvis below the bifurcation of the common iliac arteries, and metastases that are outside of the true pelvis, most commonly bone and in advanced disease, lung, and liver (21).

\section{PRECURSOR OF PROSTATE CANCER}

Prostate cancer involves the transformation of benign epithelial cells into their malignant phenotype. The most frequent process of cancer transformation in the prostate is called prostatic intraepithelial neoplasia (PIN) (22). PIN is a multicentric condition and is defined as the "neoplastic growth within the pre-existing benign epithelium of the acini or ducts" (23). PIN can be divided into two grades, 

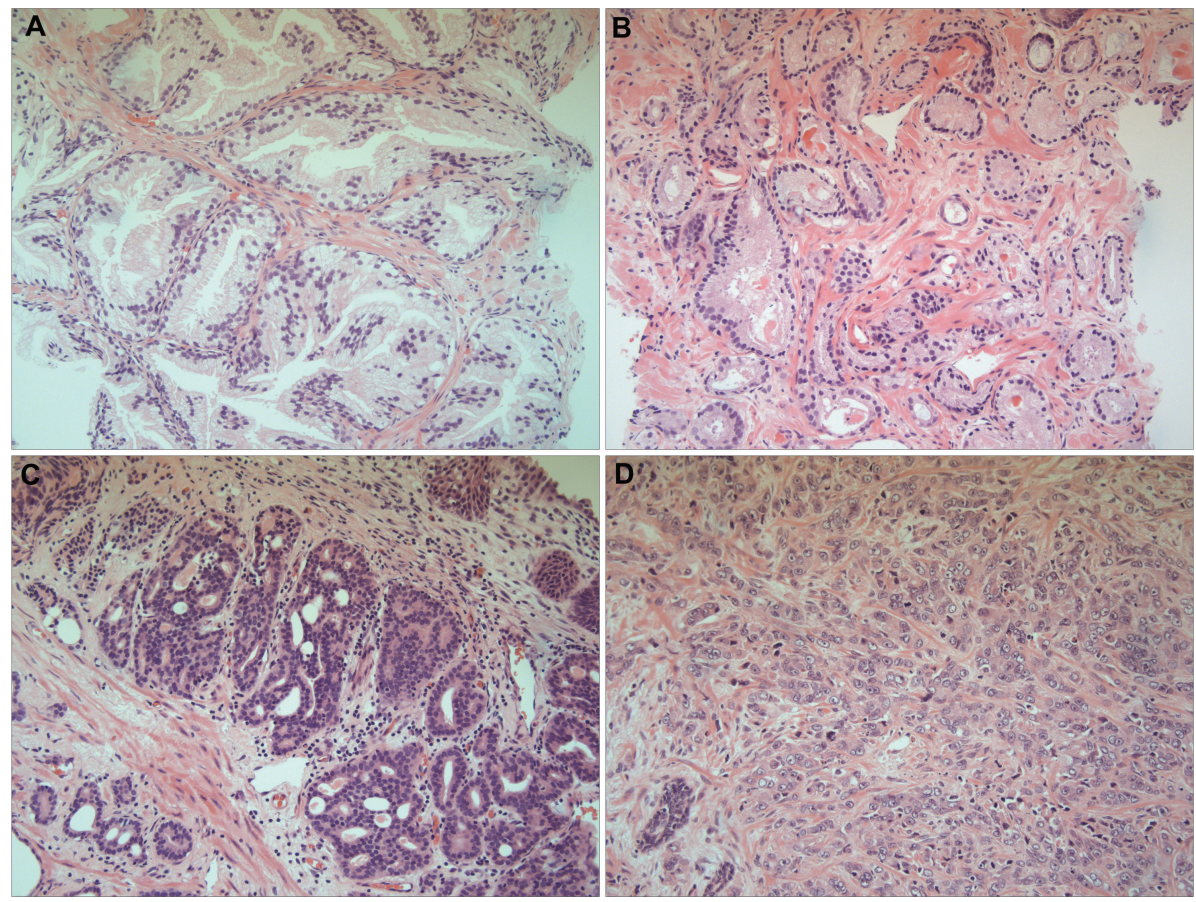

Figure 1. Prostate histology in Gleason grading groups. Gleason scoring allows physicians to predict the prognosis of patients by assessing the histological patterns of their disease.

A. Normal prostate tissue showing well-formed and well demarcated glands. B. Grade Score 3 prostatic glands are well-formed and individualized meaning they are well delineated with a clear stroma. C. Gleason Score 4 glands become fused together, are poorly formed, and show a cribriform pattern. D. Gleason Score 5 there is a lack of gland formation and the presence of individual cells. This particular section also demonstrates cytoplasmic vacuoles. (Images kindly provided by Dr. Maria Bahhadi-Hardo, Consultant Histopathologist, Frimley Park Hospital, Frimley Surrey, UK).

low (LGPIN) and high (HGPIN). HGPIN has a high predictive value for predicting progression to adenocarcinoma. HGPIN can only be detected on needle biopsy, it does not raise serum PSA levels and is not identified on transrectal ultrasound (TRUS) $(24,25)$. Histologically there are four main findings: micropapillary, tufting, cribriform and flat (25). These findings are of diagnostic value only and their individual presence/absence does not predict tumor aggressiveness (25). The basal cell layer is mostly intact in HGPIN with minimal stromal invasion. HGPIN is clinically significant, with patients requiring repeat biopsy as surveillance, with a recommended interval of 3-6 months for 2 years then yearly for life (26). Multiple studies have reported HGPIN as a significant predictor for occurrence of prostate cancer (22-58\%), therefore the presence of HGPIN on biopsy may warrant therapeutic treatment in the future (25). 


\section{TABLE 1 Gleason grading groups $(19,20)$}

Grade group 1: Gleason score $\leq 6$

Only individual discrete well-formed glands

96\% 5-year BCR free progression

Grade group 2: Gleason score 3+4 = 7

Predominantly well-formed glands with lesser component of poorly formed/fused/cribriform glands 88\% 5-year BCR free progression

Grade group 3: Gleason score 4+3 = 7

Predominantly poorly formed/fused/cribriform glands with lesser component of well-formed glands 63\% 5-year BCR free progression

Grade group 4: Gleason score 4+4 = 8; 3+5 = 8; or $5+3=8$

Only poorly formed/fused/cribriform glands, OR Predominantly well-formed glands and lesser component lacking glands, or Predominantly lacking glands and lesser component of well-formed glands

48\% 5-year BCR free progression

Grade group 5: Gleason scores 9-10

Lack gland formation (or with necrosis) with or without poorly formed/fused/cribriform glands

26\% 5-year BCR free progression

\section{ANDROGENIC REGULATION OF PROSTATE CANCER}

ARs are essential transcription factors in the regulation of male sexual development and accessory sexual organ maintenance (27). Prostate cancer growth and disease progression is initially dependent on AR activation, via testosterone and dihydrotestosterone (DHT), leading to nuclear translocation of the receptor and subsequent binding to androgen response elements (AREs) initiating transcription of genes that regulate cellular differentiation, proliferation and apoptosis (28) (Figure 2). Therefore, AR stimulation is integral to the maintenance and survival of prostate luminal epithelial cells. The hypothalamic-pituitary-gonadal (HPG) axis regulates the production of androgens. Androgens are primarily produced in Leydig cells of the testes under the regulation of luteinizing hormone (LH) secreted by the anterior pituitary gland, which in turn is regulated by gonadotropin-releasing hormone (GnRH). Testosterone is converted into DHT in the epithelial cells of the prostate by $5 \alpha$-reductase which acts as a potent ligand to cytoplasmic ARs.

Studies have failed to establish a link between raised serum levels of androgens and prostate cancer (29). In fact, high androgen levels are linked to reduced risk of aggressive prostate cancer, whilst patients with low serum androgen levels have higher risk of prostate cancer recurrence and advanced pathology (30). In lowandrogen environments, there is a selective pressure for luminal cells to become androgen-independent in order to survive. Therefore, ARs are important clinically as they are seen as integral to the progression of disease in prostate cancer. Due to its role in the development, maintenance and secretory functions of the prostate, the HPG axis is a therapeutic target in the treatment of prostate cancer (31). 


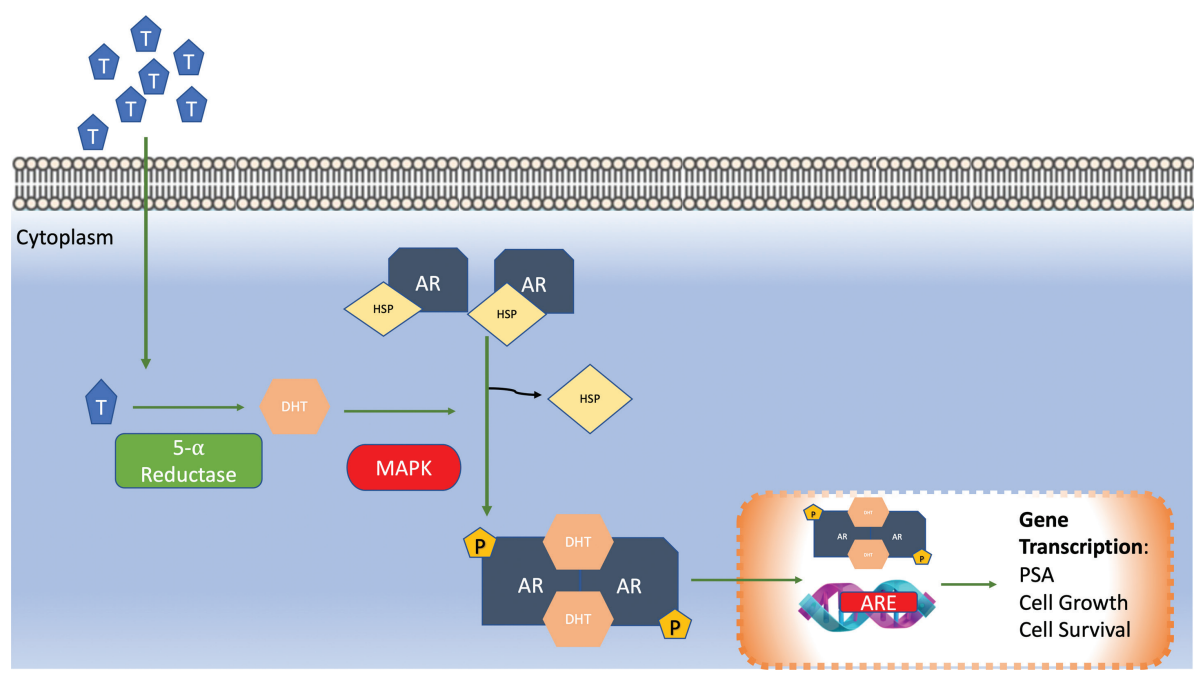

Figure 2. Androgenic regulation of prostate cancer. In the cytoplasm, activity of ARs is regulated by ligand-binding and heat shock proteins (HSP). Testosterone (T) is transported into the cytoplasm of androgen-receptive cells and is converted to DHT by 5- $\alpha$ reductase. DHT ligand binding leads to dissociation from HSP, MAPK then phosphorylates the receptor, this is followed by dimerization. The AR dimer then translocates into the nucleus where it binds to androgen response elements (AREs) in the DNA activating transcription of elements that are essential for cell growth and survival.

ARs have four functional domains: an amino-terminal transcription activation domain (NTD), a DNA-binding domain (DBD) that fastens the AR to the ARE of AR-regulated genes, a hinge region, and a C-terminal ligand-binding domain (LBD) that contains a ligand-binding pocket (LBP) that binds to androgens. When a ligand is bound, the LBD undergoes a conformational change allowing it to recruit co-factors, recognize the DNA sequences, along with the NTD, and initiate the transcription of these genes (such as PSA) and facilitating male sexual development (32). ARs have two active functional domains (AFs) that initiate transcription when activated (33). AF-1 is present in the NTD and its activation is androgen independent. AF-2 is located in the LBD and is androgen liganddependent (34). The LBP of the LBD is a therapeutic target and is targeted with treatments such as bicalutamide. AF-1 may enable cross-coupling between androgenic and growth factor signaling pathways (33). Therefore, these AFs are deemed clinically important as they could provide the key to understanding castrationresistant prostate cancer (CRPC).

\section{THEORETICAL PATHWAYS IN THE PROGRESSION TO CASTRATION-RESISTANT PROSTATE CANCER}

Androgenic blockade, through LBP and $5 \alpha$-reductase antagonists, as well as HPG overstimulation via LH/GnRH analogues, leads to epithelial cell apoptosis and a 
transient response in preventing proliferation in prostate cancer treatment. Patients will inevitably develop CRPC and thus develop a more lethal form of prostate cancer. However, the distinct pathological processes involved in this transformation is yet to be fully described as it is likely to involve a multitude of mechanisms. Studies have reported AR mutations play an important role in the malignant potential of CRPC and that androgen-independent prostate cancer cells exhibit high levels of $A R$ genetic amplification (35). AR mutations in primary prostate cancer are rare, however these mutations are prevalent in CRPC $(50 \%)$ $(36,37)$. The AR gene mutations database describes 1029 associated AR mutations, of which 159 are related to predisposing men to prostate cancer (38). These mutations lead to alterations that improve the functional activity of the receptor, such as increased AR sensitivity to low levels of ligand $(35,39)$, non-androgen ligand binding, ligand-independent activation as well as AR-independent pathways (32). Further studies and meta-analyses have identified that shortened AR CAG-repeats in the NTD may increase the risk of prostate cancer (32) and the genetic links are further supported by familial risk, with men having 2-4 times risk if a first-degree relative has prostate cancer (40).

\section{ANDROGEN RECEPTOR 'CROSS-TALK’ WITH PEPTIDE GROWTH FACTORS}

AR-independent pathways include alternative peptide growth factors including transforming growth factor- $\beta$ (TGF- $\beta$ ), epidermal growth factor (EGF), fibroblast growth factor (FGF) and insulin-like growth factor (IGF) $(41,42)$. These peptide factors help facilitate the AR-regulated proliferation of prostate epithelial cells via a process called 'cross-talk' (42). For instance, EGF, alongside its membraneassociated tyrosine receptor kinase EGF-1 (EGFR, HERI), is involved in the motility and invasiveness of cancer cells through enhanced migration through extracellular matrix barriers, basal membranes and then the subsequent cellular proliferation (43). ErbB2 (HER2), a member of the EGFR family, is upregulated in CRPC and has been associated with androgen-independent transcriptional activation of ARs and the subsequent heightened expression of PSA (29). HER2/neu receptors, part of the EGFR family, are found overexpressed in breast and ovarian cancers. They have been proposed as a mechanism for AR-independent activation in CRPC (44). In vitro and in vivo studies involving forced overexpression of HER2/ neu receptors or transfection of HER2/neu in prostate cancer cell lines (LNCaP) identified promotion to AR-independence and expression of PSA $(44,45)$.

\section{ANDROGEN RECEPTOR BYPASS PATHWAYS}

The reduction in AR activation leads to hypersensitization of other pathways. For instance, the upregulation in IGF-1, EGF and other growth factors subsequently activate ErbB2 and other tyrosine receptor kinases (32). This results in the activation of phosphatidylinositol 3-kinase (PI3K) and subsequent PI3KAKT-mTOR pathway $(46,47)$. PI3K activation, converts phosphatidylinositol 


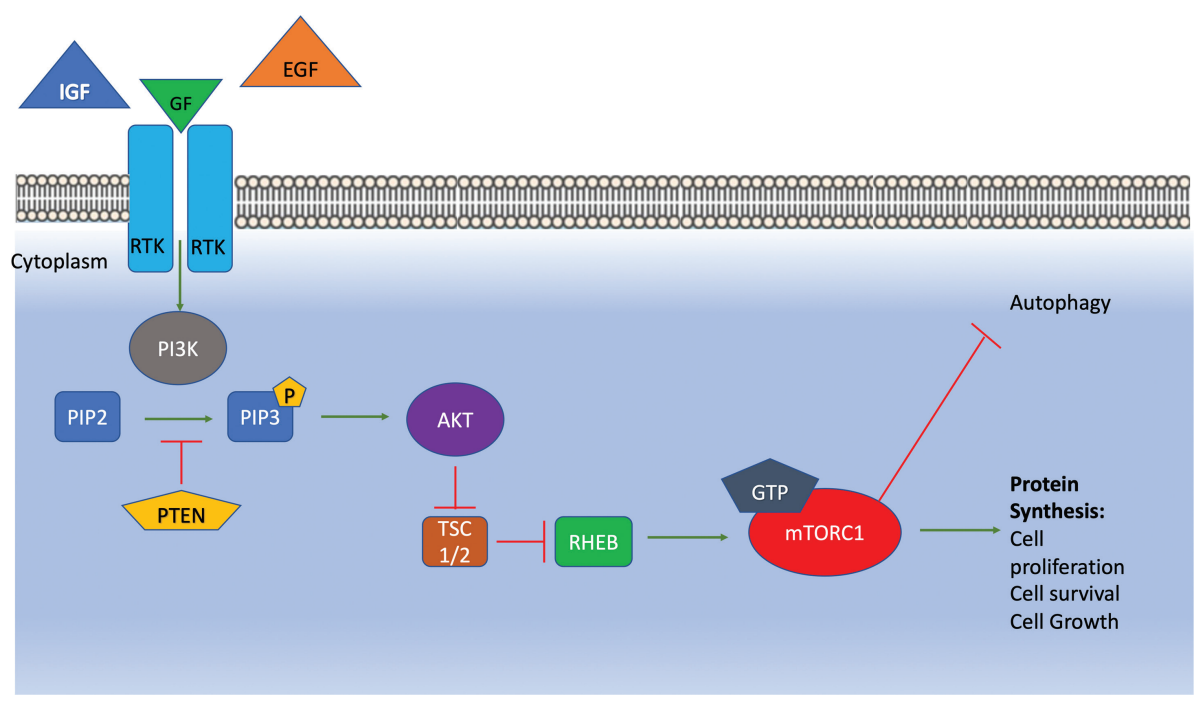

Figure 3. Androgen receptor bypass pathways. Reduced AR suppression leads to the upregulation of Tyrosine Receptor Kinases (RTK) e.g., ErbB2 by factors such as IGF, GF and EGF. RTK activation leads to the stimulation of PI3K with phosphorylates PIP2 into PIP3. This process is inhibited by the tumor suppressor PTEN. PIP3 activates AKT which indirectly suppresses the activity of the cell survival protein mTORC1 by inhibiting TSC1/2 which in turn suppresses the GTP-binding protein RHEB. mTORC1 is pivotal in the translation of proteins and therefore protein synthesis. Therefore, AR inhibition, as well as PTEN suppression, leads to overactivation of the PIP3-AKT-mTOR pathway - creating an alternate route for cell survival in CRPC.

4,5-bisphosphonate (PIP2) to phosphatidylinositol 3-5-triphosphate (PIP3) which recruits protein kinase B (AKT) proteins to the luminal cell cytoplasm (46). AKT signaling involves deregulating the tuberous sclerosis $1 / 2$ (TSCl/2), an inhibitor of the GTP-binding protein RHEB, which in turn is responsible for the activation of the mechanistic target of rapamycin complex 1 (mTORCl), a kinase that is critical to the regulation of cell cycle. mTORCl impedes autophagy and promoting prostate cancer cellular proliferation (Figure 3) (46). Through this pathway, studies have proven that IGF-l can activate AR-mediated gene transcription and stimulate the production of PSA in LNCaP cells. As a result, the PI3K-AKT-mTOR pathway is of interest in establishing new therapeutic targets for patients with CRPC $(47,48)$.

\section{THE ROLE OF TUMOR SUPPRESSOR GENE PTEN IN PROSTATE CANCER}

Genetic analysis of CRPC tumors has identified that the gene for the protein phosphatase and tensin homolog (PTEN) is mutated in $20 \%$ of cases (49). PTEN is a tumor suppressor gene, it acts by negatively regulating the PI3K-AKT-mTOR pathway and halting the cell-cycle at the $G_{1}$ stage therefore halting cellular 
proliferation. Loss of PTEN thus results in an increase in the PI3K-AKT-mTOR pathway as well as impairing normal AR regulation, resulting in increased cellular proliferation, AR expression and reduced apoptosis (29). PTEN's expression is inversely correlated with Gleason Score and therefore is associated significantly with aggressive prostate cancer (Gleason $\geq 7, \mathrm{P}=0.0004$ ), with up to $20 \%$ of highgrade tumors being negative for PTEN expression (50).

\section{TUMOR MICROENVIRONMENT IN PROSTATE CANCER}

The tumor microenvironment (TME) describes the vast array of supporting cells (including immune cells, fibroblasts, adipose cells, microvasculature, and components of the extracellular matrix [ECM]) that form a complex network surrounding tumor cells that may play a role in their pathogenicity, especially involving their transition from normal cells to neoplastic cancer cells themselves $(51,52)$. Studies have reported that tumor cells are able to 'hijack' immune cells and prime them to aid metastatic potential (51). As studied by Chen et al. (53), immune cells can be infiltrated by tumor cells forming tumor-associated macrophages (TAMs). They identified that CD8-T cells can express PSA in aggressive forms of prostate cancer, and this perhaps enhances the tumor's ability to metastasize to lymphatic tissue and bone. Therefore, the TME may provide the environment whereby alternative cell types transform into malignant tumor cells in aggressive prostate cancer and influence the ability to invade local and systemic structures (54).

\section{APOPTOSIS REGULATION}

Dysregulation in the programmed cell death mechanisms (apoptosis) is important in the pathogenesis of prostate cancer and is deemed a key driver in the exponential growth of tumor cells (55). There are two distinct pathways, intrinsic and extrinsic, that are involved in the normal signaling of programmed cell death that are critical to tissue homeostasis. Extrinsic (receptor pathway) mechanisms involve the intracellular binding of apoptosis-inducing ligands, such as tumor necrosis factor (TNF), to cell-surface death receptors that are part of the TNF-R superfamily such as CD95 (Apo-1/Fas) or TNF-related apoptosis-inducing ligand (TRAIL) receptors. These receptors contain the Fas-associated death domain (FADD) and form death-inducing signaling complexes (DISCs) with intracellular caspases that contain a death-effector domain (DED) such as caspases 8 and 10 $(56,57)$. Effector caspases, including caspase-3, activate proteolysis and cleavage of intracellular/intranuclear substrates, inducing apoptosis (56).

Intrinsic (mitochondrial pathway) mechanisms involve the activation of mitochondria through intracellular damage such as DNA damage via chemoradiotherapy. Intracellular insults result in the p53 activation of the pro-apoptotic B-cell lymphoma 2 (Bcl-2) family (including Bax, Bid and Bad) that induce mitochondrial release of cytochrome $c$ (Cyc-c) (58). Cyc-c is a key component, alongside procaspase 9 and apoptotic protease activating factor-1 (Apaf-1), that form an apoptosome, an apoptosis inducing complex (59). The apoptosome then converges alongside the extrinsic pathway in activating caspase-3. 
Bcl-2 family members such as Bax, Bid and Bad are proapoptotic factors that target the mitochondrial membrane and facilitate Cyc-c release. However, Bcl-2 is permanently anchored to the mitochondrial wall, is anti-apoptotic and prevent the release of Cyc-c (55). Therefore, the Bcl-2 family work in homeostasis to regulate cellular death. In aggressive prostate cancer, Bcl-2 is upregulated, swinging the homeostatic balance firmly towards anti-apoptosis (60). This overexpression is seen in chemoradiotherapy-resistant prostate cancer phenotypes, therefore can be seen as a key indicator in the prognosis of aggressive prostate cancer $(55,60)$. Upstream of Bcl-2 family receptors, mutations of the $p 53$ tumor suppressor gene are also characteristic of malignant prostate cancer and CRPC, further highlighting the critical role of apoptosis in pathogenicity (61). The true genetic and molecular pathophysiology of prostate cancer is a complex topic. Unlike breast cancer, there are no highly penetrant and dominating genetic mutations that account for the majority of prostate cancer cases. Thus, there is huge scope for future therapeutic innovation and bespoke genetic analysis may well play a role in reducing the prevalence of CRPC.

\section{CONCLUSION}

Prostate cancer is a multi-factorial disease entity that is still incompletely understood. A major problem is the current difficulty in assessing risk of progression of the disease which can have a relatively benign course or be rapidly spreading to other tissues with fatal consequences. Expansion of our knowledge of the pathogenesis of prostate cancer is essential if our search for truly predictive markers, and tissue assessments, is to lead to a rapid understanding of potential clinical outcome of a tumor of the prostate, and for the development and use of highly effective treatments that do not lead to some patients being negatively affected by unnecessary procedures and diagnoses.

Conflict of interest: The author declares no potential conflicts of interest with respect to research, authorship and/or publication of this article.

Copyright and permission statement: The author confirms that the materials included in this chapter do not violate copyright laws. Where relevant, appropriate permissions have been obtained from the original copyright holder(s), and all original sources have been appropriately acknowledged or referenced.

\section{REFERENCES}

1. UK CR. Prostate Cancer Mortality Statistics 2021 [Available from: https://www.cancerresearchuk.org/ health-professional/cancer-statistics/statistics-by-cancer-type/prostate-cancer/mortality [Accessed on 10 April 2021]

2. Sánchez-Chapado M, Olmedilla G, Cabeza M, Donat E, Ruiz A. Prevalence of prostate cancer and prostatic intraepithelial neoplasia in Caucasian Mediterranean males: an autopsy study. Prostate. 2003;54(3):238-47. https://doi.org/10.1002/pros.10177 
3. Brawley OW. Prostate cancer epidemiology in the United States. World J Urol 2012;30(2):195-200. https://doi.org/10.1007/s00345-012-0824-2

4. Mishra SC. A discussion on controversies and ethical dilemmas in prostate cancer screening. J Med Ethics. 2021;47(3):152-8. https://doi.org/10.1136/medethics-2019-105979

5. Bray F, Ferlay J, Soerjomataram I, Siegel RL, Torre LA, Jemal A. Global cancer statistics 2018: GLOBOCAN estimates of incidence and mortality worldwide for 36 cancers in 185 countries. CA: A Cancer J Clin. 2018;68(6):394-424. https://doi.org/10.3322/caac.21492

6. Barry MJ. Screening for prostate cancer--the controversy that refuses to die. N Engl J Med. 2009;360(13):1351. https://doi.org/10.1056/NEJMe0901166

7. Gentile F, Ferro M, Della Ventura B, La Civita E, Liotti A, Cennamo M, et al. Optimized Identification of High-Grade Prostate Cancer by Combining Different PSA Molecular Forms and PSA Density in a Deep Learning Model. Diagnostics. 2021;11(2):335. https://doi.org/10.3390/diagnostics11020335

8. Toivanen R, Shen MM. Prostate organogenesis: tissue induction, hormonal regulation and cell type specification. Development. 2017;144(8):1382-98. https://doi.org/10.1242/dev.148270

9. Karhadkar SS, Steven Bova G, Abdallah N, Dhara S, Gardner D, Maitra A, et al. Hedgehog signalling in prostate regeneration, neoplasia and metastasis. Nature. 2004;431(7009):707-12. https://doi. org/10.1038/nature02962

10. Fan L, Pepicelli CV, Dibble CC, Catbagan W, Zarycki JL, Laciak R, et al. Hedgehog Signaling Promotes Prostate Xenograft Tumor Growth. Endocrinology. 2004;145(8):3961-70. https://doi.org/10.1210/ en.2004-0079

11. Shaw A, Gipp J, Bushman W. The Sonic Hedgehog pathway stimulates prostate tumor growth by paracrine signaling and recapitulates embryonic gene expression in tumor myofibroblasts. Oncogene. 2009;28(50):4480-90. https://doi.org/10.1038/onc.2009.294

12. Humphrey PA. Histopathology of prostate cancer. Cold Spring Harb Perspect Med. 2017;7(10):a030411. https://doi.org/10.1101/cshperspect.a030411

13. Lee SH, Shen MM. Cell types of origin for prostate cancer. Curr Opin Cell Biol. 2015;37:35-41. https://doi.org/10.1016/j.ceb.2015.10.002

14. Blagoev KB, Iordanov R, Zhou M, Fojo T, Bates SE. Drug resistant cells with very large proliferative potential grow exponentially in metastatic prostate cancer. Oncotarget. 2020;12(1). https://doi. org/10.18632/oncotarget.27855

15. Wang Z, Shen M. Revisiting the concept of cancer stem cells in prostate cancer. Oncogene. 2011;30(11):1261-71. https://doi.org/10.1038/onc.2010.530

16. Wang ZA, Mitrofanova A, Bergren SK, Abate-Shen C, Cardiff RD, Califano A, et al. Lineage analysis of basal epithelial cells reveals their unexpected plasticity and supports a cell-of-origin model for prostate cancer heterogeneity. Nat Cell Biol. 2013;15(3):274-83. https://doi.org/10.1038/ncb2697

17. Alizadeh M, Alizadeh S. Survey of clinical and pathological characteristics and outcomes of patients with prostate cancer. Glob J Health Sci. 2014;6(7):49. https://doi.org/10.5539/gjhs.v6n7p49

18. Humphrey PA, Moch H, Cubilla AL, Ulbright TM, Reuter VE. The 2016 WHO Classification of Tumours of the Urinary System and Male Genital Organs-Part B: Prostate and Bladder Tumours. Eur Urol. 2016;70(1):106-19. https://doi.org/10.1016/j.eururo.2016.02.028

19. Epstein JI, Egevad L, Amin MB, Delahunt B, Srigley JR, Humphrey PA. The 2014 International Society of Urological Pathology (ISUP) Consensus Conference on Gleason Grading of Prostatic Carcinoma: Definition of Grading Patterns and Proposal for a New Grading System. Am J Surg Pathol. 2016;40(2):244-52. https://doi.org/10.1097/PAS.0000000000000530

20. Barakzai MA. Prostatic Adenocarcinoma: A Grading from Gleason to the New Grade-Group System: A Historical and Critical Review. Asian Pac J Cancer Prev. 2019;20(3):661-6. https://doi.org/10.31557/ APJCP.2019.20.3.661

21. Buyyounouski MK, Choyke PL, McKenney JK, Sartor O, Sandler HM, Amin MB, et al. Prostate cancer major changes in the American Joint Committee on Cancer eighth edition cancer staging manual. CA: Cancer J Clin 2017;67(3):245-53. https://doi.org/10.3322/caac.21391

22. Brawer MK. Prostatic intraepithelial neoplasia: an overview. Rev Urol. 2005;7 Suppl 3(Suppl 3): S11-S8. 
23. Kim HL, Yang XJ. Prevalence of high-grade prostatic intraepithelial neoplasia and its relationship to serum prostate specific antigen. Int Braz J Urol. 2002;28(5):413-6.

24. Alexander EE, Qian J, Wollan PC, Myers RP, Bostwick DG. Prostatic intraepithelial neoplasia does not appear to raise serum prostate-specific antigen concentration. Urology. 1996;47(5):693-8. https:// doi.org/10.1016/S0090-4295(96)00004-0

25. Bostwick DG, Qian J. High-grade prostatic intraepithelial neoplasia. Mod Pathol. 2004;17(3):360-79. https://doi.org/10.1038/modpathol.3800053

26. Bostwick DG. Prostatic intraepithelial neoplasia (PIN): current concepts. J Cell Biochem. 1992;50(S16H):10-9. https://doi.org/10.1002/jcb.240501205

27. Culig Z, Klocker H, Bartsch G, Hobisch A. Androgen receptors in prostate cancer. Endocr-Relat Cancer. 2002;9(3):155-70. https://doi.org/10.1677/erc.0.0090155

28. Hodges $C$. Studies on prostatic cancer I. the effect of castration, of estrogen and of androgen injection on serum phosphatases in metastatic carcinoma of the prostate. Cancer Res. 1941;1(4):293-7.

29. Heinlein CA, Chang C. Androgen receptor in prostate cancer. Endocr Rev. 2004;25(2):276-308. https://doi.org/10.1210/er.2002-0032

30. Corona G, Baldi E, Maggi M. Androgen regulation of prostate cancer: where are we now? J Endocrinol Investig. 2011;34(3):232-43. https://doi.org/10.1007/BF03347072

31. Schleutker J. Polymorphisms in androgen signaling pathway predisposing to prostate cancer. Mol Cell Endocrinol. 2012;360(1):25-37. https://doi.org/10.1016/j.mce.2011.07.007

32. Tan MHE, Li J, Xu HE, Melcher K, Yong E-l. Androgen receptor: structure, role in prostate cancer and drug discovery. Acta Pharmacol Sin. 2015;36(1):3-23. https://doi.org/10.1038/aps.2014.18

33. Bevan C, Parker M. The Role of Coactivators in Steroid Hormone Action. Exp Cell Res. 1999;253(2):349-56. https://doi.org/10.1006/excr.1999.4719

34. Girling JS, Whitaker HC, Mills IG, Neal DE. Pathogenesis of prostate cancer and hormone refractory prostate cancer. Indian J Urol. 2007;23(1):35-42. https://doi.org/10.4103/0970-1591.30265

35. Taplin M-E, Bubley GJ, Shuster TD, Frantz ME, Spooner AE, Ogata GK, et al. Mutation of the androgen-receptor gene in metastatic androgen-independent prostate cancer. $\mathrm{N}$ Engl J Med. 1995;332(21):1393-8. https://doi.org/10.1056/NEJM199505253322101

36. Chen CD, Welsbie DS, Tran C, Baek SH, Chen R, Vessella R, et al. Molecular determinants of resistance to antiandrogen therapy. Nat Med. 2004;10(1):33-9. https://doi.org/10.1038/nm972

37. Visakorpi T, Hyytinen E, Koivisto P, Tanner M, Keinänen R, Palmberg C, et al. In vivo amplification of the androgen receptor gene and progression of human prostate cancer. Nat Genet. 1995;9(4):401-6. https://doi.org/10.1038/ng0495-401

38. Gottlieb B, Beitel LK, Nadarajah A, Paliouras M, Trifiro M. The androgen receptor gene mutations database: 2012 update. Hum Mutat. 2012;33(5):887-94. https://doi.org/10.1002/humu.22046

39. Koivisto P, Kononen J, Palmberg C, Tammela T, Hyytinen E, Isola J, et al. Androgen receptor gene amplification: a possible molecular mechanism for androgen deprivation therapy failure in prostate cancer. Cancer Res. 1997;57(2):314-9.

40. Stanford JL, Ostrander EA. Familial prostate cancer. Epidemiol Rev. 2001;23(1):19-23. https://doi. org/10.1093/oxfordjournals.epirev.a000789

41. Velcheti V, Karnik S, Bardot SF, Prakash O. Pathogenesis of prostate cancer: lessons from basic research. Ochsner J. 2008;8(4):213-8.

42. Zhu ML, Kyprianou N. Androgen receptor and growth factor signaling cross-talk in prostate cancer cells. Endocr Relat Cancer. 2008;15(4):841-9. https://doi.org/10.1677/ERC-08-0084

43. Wells A, Kassis J, Solava J, Turner T, Lauffenburger DA. Growth Factor-Induced Cell Motility in Tumor Invasion. Acta Oncol. 2002;41(2):124-30. https://doi.org/10.1080/028418602753669481

44. Craft N, Shostak Y, Carey M, Sawyers CL. A mechanism for hormone-independent prostate cancer through modulation of androgen receptor signaling by the HER-2/neu tyrosine kinase. Nat Med. 1999;5(3):280-5. https://doi.org/10.1038/6495

45. Yeh S, Lin HK, Kang HY, Thin TH, Lin MF, Chang C. From HER2/Neu signal cascade to androgen receptor and its coactivators: a novel pathway by induction of androgen target genes through MAP kinase in prostate cancer cells. Proc Natl Acad Sci U S A. 1999;96(10):5458-63. https://doi. org/10.1073/pnas.96.10.5458 
46. Sarker D, Reid AHM, Yap TA, de Bono JS. Targeting the PI3K/AKT Pathway for the Treatment of Prostate Cancer. Clin Cancer Res. 2009;15(15):4799-805. https://doi.org/10.1158/1078-0432. CCR-08-0125

47. Shorning BY, Dass MS, Smalley MJ, Pearson HB. The PI3K-AKT-mTOR Pathway and Prostate Cancer: At the Crossroads of AR, MAPK, and WNT Signaling. Int J Mol Sci. 2020;21(12):4507. https://doi. org/10.3390/ijms21124507

48. Culig Z, Hobisch A, Cronauer MV, Radmayr C, Trapman J, Hittmair A, et al. Androgen receptor activation in prostatic tumor cell lines by insulin-like growth factor-I, keratinocyte growth factor, and epidermal growth factor. Cancer Res. 1994;54(20):5474-8.

49. Bookstein R. Tumor suppressor genes in prostate cancer. Prostate Cancer: Springer; 2001. p. 61-94. https://doi.org/10.1385/1-59259-009-8:61

50. McMenamin ME, Soung P, Perera S, Kaplan I, Loda M, Sellers WR. Loss of PTEN expression in paraffin-embedded primary prostate cancer correlates with high Gleason score and advanced stage. Cancer Res. 1999;59(17):4291-6.

51. Thienger P, Rubin MA. Prostate cancer hijacks the microenvironment. Nat Cell Biol. 2021;23(1):3-5. https://doi.org/10.1038/s41556-020-00616-3

52. Gevaert T, Van Eycke Y-R, Vanden Broeck T, Van Poppel H, Salmon I, Rorive S, et al. The potential of tumour microenvironment markers to stratify the risk of recurrence in prostate cancer patients. PLOS One. 2021;15(12):e0244663. https://doi.org/10.1371/journal.pone.0244663

53. Chen S, Zhu G, Yang Y, Wang F, Xiao Y-T, Zhang N, et al. Single-cell analysis reveals transcriptomic remodellings in distinct cell types that contribute to human prostate cancer progression. Nat Cell Biol. 2021;23(1):87-98. https://doi.org/10.1038/s41556-020-00613-6

54. Ganguly SS, Li X, Miranti CK. The Host Microenvironment Influences Prostate Cancer Invasion, Systemic Spread, Bone Colonization, and Osteoblastic Metastasis. Front Oncol 2014;4(364). https:// doi.org/10.3389/fonc.2014.00364

55. McKenzie S, Kyprianou N. Apoptosis evasion: the role of survival pathways in prostate cancer progression and therapeutic resistance. J Cell Biochem. 2006;97(1):18-32. https://doi.org/10.1002/ jcb.20634

56. Debatin K-M, Krammer PH. Death receptors in chemotherapy and cancer. Oncogene. 2004:23(16):2950-66. https://doi.org/10.1038/sj.onc.1207558

57. Krammer PH. CD95's deadly mission in the immune system. Nature. 2000;407(6805):789-95. https://doi.org/10.1038/35037728

58. DiPaola RS, Patel J, Rafi MM. Targeting apoptosis in prostate cancer. Hematol Oncol Clin North Am 2001;15(3):509-24. https://doi.org/10.1016/S0889-8588(05)70229-X

59. Hengartner MO. The biochemistry of apoptosis. Nature. 2000;407(6805):770-6. https://doi. org/10.1038/35037710

60. McCarty MF. Targeting multiple signaling pathways as a strategy for managing prostate cancer: multifocal signal modulation therapy. Integr Cancer Ther. 2004;3(4):349-80. https://doi. org/10.1177/1534735404270757

61. Navone NM, Troncoso P, Pisters LL, Goodrow TL, Palmer JL, Nichols WW, et al. p53 protein accumulation and gene mutation in the progression of human prostate carcinoma. J Natl Cancer Inst. 1993;85(20):1657-69. https://doi.org/10.1093/jnci/85.20.1657 
